\title{
Mathematical and Numerical Modeling of Type N Thermocouple
}

\author{
Tanmoy Chakraborty", Ravikiran Kadoli \\ Department of Mechanical Engineering National Institute of Technology, Karnataka \\ *Corresponding Author: tanmoy.chakraborty19@gmail.com
}

Copyright $@ 2014$ Horizon Research Publishing All rights reserved

\begin{abstract}
This paper presents the mathematical and numerical modelling of type $\mathrm{N}$ thermocouple using the transient diffusion phenomenon and finite difference and finite volume concept. Here particles of 5 inert atmospheres employed for checking the effect of drag force on sheath mass and to recommend one media for numerical model calculation. Environment is hot for which concentration of sheath particle increase near sheath but decrease as distance increase. Von-Neumann stability incorporates for time step calculation in numerical work.
\end{abstract}

Keywords Sheath Mass, Transient Diffusion, Hot Media, Inert Atmosphere, Type N

\section{Introduction}

Here we have taken type $\mathrm{N}$ thermocouple i.e. Nicrosil-Nisil which shows good thermoelectric stability at high temperature like $1300^{\circ} \mathrm{C}$ [12][13]. We have chosen exposed Mineral insulated metal sheath type thermocouple [8] [9] for studying the particle effect on the outer sheath of the thermocouple. Generally what happen stars are moving with space and time in the galaxy like rubber band their locus increasing with space and time and they are moving to the one galaxy to another as universe has infinite space and similarly here also particle mass extracted due to drag force of the hot media's particle transferred to other space with time. But our situation involved Brownian motion for which the concentration of the particle reduced with distance from the sheath contact point. We are taking five media Air-Ar, Air-He, Air-Kr, Air-Ne, and Air-Xe for studying the drag and velocity effect of the particles of that media on the sheath mass. Temperature is varies between $1000^{\circ} \mathrm{C}-1500^{\circ} \mathrm{C}$ and pressure 1 atmosphere. Sizes of the composite media's can be found from Poling et al book "The properties of gases and liquids" [7]. Since the concentration of the particle mass varies with space and time we here incorporating transient diffusion of the particle and analytically solved with specific boundary condition by applying application of derivatives concept and numerically we get the variation of concentration at each grid with time by incorporating concept of finite difference and finite volume method. After that recommendation of one media has to be done for numerical work validation incorporating von-Neumann stability criterion. The fig. 1 of the system is as follows

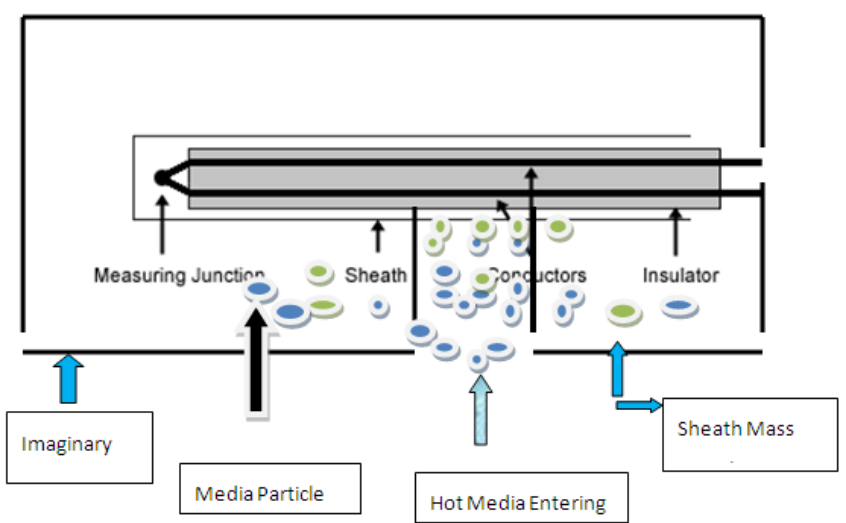

Figure 1. 2D boundary where hot mass in entering through imaginary boundary to sheath of thermocouple. [3]

We are taking that imaginary boundary from the above picture for grid calculation taking the region of sheath contact and region of atm. Difference $1 \mathrm{~m}$ and 10 grids.

\section{Literature Review}

According to the Platinum Metals Rev., 1969 \& 1971 long term calibration changes of $\mathrm{Rh}-\mathrm{Pt}$ thermocouple which is operating close to high temperature above $1300^{\circ} \mathrm{C}$ environment and rhodium transferred in vapour phase slowly from the positive to the negative limb which affects the thermoelectric behaviour. The accumulation of serious concentrations of rhodium oxide prevented by employing the natural convection and ventilation occurs in the assembly and selection of suitable alloys reduced the harmful effects of rhodium vapour migration. But it is seen that majority of Rhodium is emitted from the outer sheath rather than from the positive leg of the unit. Now for minimising such kind of effects the unstable thermocouples are sectioned for micro-examination which deals with cracks and fissures etc. 
It is important to emphasise the geometry of the thermocouple system with respect to stability. There are four arrangement such as in line where is no contamination of the negative limb, parallel where is some cross contamination, minimised by convection, twin bore insulated where is local cross contamination at insulator junctions and fully insulated where is moderate to severe contamination of the platinum limb encouraged by stagnant temperature takes place. The performance of argon-filled units is not affected by insulant quality. [5][6][10]

\section{Analytical Model}

As we told earlier we are taking a situation where thermocouple of MIMS (mineral insulated metal sheath) is exposed to the environment in a 2D boundary where the hot gas is entering. Here we have chosen five systems for checking maximum drag effect on the particle mass. Drag force of the system more means it can deplete outer sheath of thermocouple more. Since sheath mass chipped or ablated due to the drag force of the media particle mass, so gravity force try to attract sheath particle mass downward for which the variation of the concentration in $\mathrm{Y}$ axis more than other axis. So for the dilute species in a stationary case by assuming no homogeneous reaction and varying diffusivity and concentration, one dimensional mass transfer in $\mathrm{Y}$ direction by relaxing the $\mathrm{Z}$ direction components\& $\mathrm{X}$ direction components in case of transient diffusion is as follows [2]

$$
\frac{\partial^{2} C}{\partial y^{2}}=\frac{1}{D} \frac{\partial C}{\partial t}
$$

Where $\mathrm{C}$ is the concentration in molecules $/ \mathrm{m}^{3}$, $\mathrm{t}$ is the time in second; $\mathrm{D}$ is the diffusivity in $\mathrm{cm}^{2} / \mathrm{s} \& \mathrm{y}$ is the space in $\mathrm{m}$. Now by invoking the concept of particle diffusivity [11] which is the function of particle size and gas properties in gases we can write equation (1) is as follows

$$
\frac{\partial^{2} N}{\partial y^{2}}=\frac{1}{D} \frac{\partial N}{\partial t}
$$

Where ' $\mathrm{N}$ ' is the number of particle mass transported upwards through the hole provided in the downward of the $2 \mathrm{D}$ boundary. Release of equally sized particle of $\mathrm{N}_{0}$ at $\mathrm{t}=0$ is increased in concentration with time as the system temperature goes on increasing from $1000^{\circ} \mathrm{C}$ to $1500^{\circ} \mathrm{C}$ i.e. beyond the melting point of type $\mathrm{N}$ thermocouple. The solution of equation (2) using application of derivatives and the boundary condition $\mathrm{N}(0, \mathrm{t}) \& \mathrm{~N}(1, \mathrm{t})$ relaxing it to zero is as follows

$$
N(y, t)=\frac{2 N_{0}}{\pi} \sum_{n=1}^{\infty} \frac{(-1)^{n+1}}{n} \sin \left(\frac{n \pi y}{l}\right) e^{-D{\frac{(n \pi)^{2}}{l}}^{2} t}
$$

Where ' $\mathrm{N}_{0}$ ' is the initial particle number in molecules $/ \mathrm{m}^{3}$, 1 is the length of the point of contact of thermocouple sheath and the entrance point of the media into the boundary in $\mathrm{m} \&$ $\mathrm{n}$ is the number of media.

As the particles motion followed Brownian motion so they collide with each other and the collision diameter, collision integral, diffusivity and drag force can be find by following formulas. The collision diameter $\left(\sigma_{\mathrm{AB}}\right)$ is the arithmetic average of the collision diameters $\left(\sigma_{A} \& \sigma_{B}\right)$ of the two species present

$$
\sigma_{A B}=\frac{1}{2}\left(\sigma_{A}+\sigma_{B}\right)
$$

The collision integral $\Omega$ can be obtained from tables when the energy of interaction $\varepsilon_{\mathrm{AB}}$ for the composite system (described by the Leonard-Jones 12-6 potential, from tables) is known.

$$
\varepsilon_{A B}=\sqrt{\varepsilon_{A} \varepsilon_{B}}
$$

Where $\varepsilon_{A} \& \varepsilon_{B}$ is the Characteristic Leonard-Jones energy of the two species present.

It is valid for pressure $<10 \mathrm{~atm}$. and $\mathrm{T}^{*}$ lies between $[0.3$, $100]$ for deviation maximum of $0.0064 \%$.

$$
\Omega_{D}=\frac{A}{T^{* B}}+\frac{C}{\exp \left(D T^{*}\right)}+\frac{E}{\exp \left(F T^{*}\right)}+\frac{G}{\exp \left(H T^{*}\right)}
$$

Where $\mathrm{T}^{*}=\mathrm{KT} / \varepsilon_{\mathrm{AB}}, \mathrm{A}=1.06036, \mathrm{~B}=0.15610, \mathrm{C}=0.19300$, $\mathrm{D}=0.47635, \mathrm{E}=1.03587, \mathrm{~F}=1.52996, \mathrm{G}=1.76474, \mathrm{H}=3.8941$

Now the mean free path expression suffers from a significant flaw - it assumes that the "target" molecules are at rest when in fact they have a high average velocity i.e. the number of collisions is 1.414 times the number with stationary targets. So mean free path $(\boldsymbol{\lambda})$ in ' $\mathrm{nm}$ ' can be evaluated as by following formula

$$
\lambda_{A B}=\frac{R T}{\sqrt{2 \pi \sigma^{2} N_{A} P}}
$$

Where $\mathrm{N}_{\mathrm{A}}=6.023 \times 10^{23}$ molecules $/ \mathrm{mol}, \mathrm{R}$ is the universal gas constant, $\mathrm{T}$ is the absolute temperature in $\mathrm{k}, \mathrm{P}$ is the pressure in bar, $\sigma$ is the characteristics length of species $A B$ in $\mathrm{A}^{0}$.

Velocity can be evaluated is as follows

$$
V_{A B}=\sqrt{\frac{8 R T}{\pi M_{A B}}}
$$

Where $\mathrm{M}_{\mathrm{AB}}$ is the composite molecular weight of the system A \& B can be evaluated as follows $M_{A B}=\frac{2}{\left(\frac{1}{M_{A}}+\frac{1}{M_{B}}\right)}$ and viscosity and diffusivity can be evaluated is as follows

$$
D_{A B}=\frac{0.00266 T^{\frac{3}{2}}}{P M_{A B}^{\frac{1}{2}} \sigma_{A B}^{2} \Omega_{D}}
$$

Where $D_{A B}$ is the diffusion coefficient in $\mathrm{cm}^{2} / \mathrm{s}$ and $\Omega_{\mathrm{D}}$ is the diffusion collision integral, dimensionless. Now viscosity can be evaluated by incorporating intermolecular effects is as follows

$$
\mathrm{AB}=26.69 \frac{(M T)^{\frac{1}{2}}}{\sigma^{2} \Omega_{D}}
$$

Where ${ }_{A B}$ is the composite system viscosity in $\mu \mathrm{p}$ and $\mathrm{M}$ is the molecular weight in $\mathrm{g} / \mathrm{mol}$.[7]

Now for drag force referring Clarkson universities model which is of national science foundation according to Brenner (1961) the drag acting on a particle moving toward a wall 
under the creeping flow condition as shown in figure 2. To the first order, the drag coefficient is given as

$$
F_{D}=\frac{3 \pi V \sigma}{C_{C}}
$$

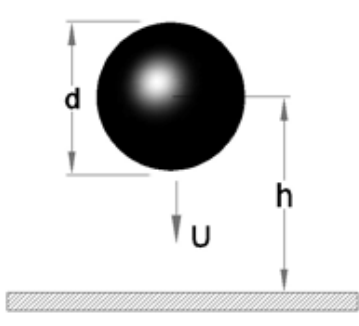

(a) Motion normal to the wall

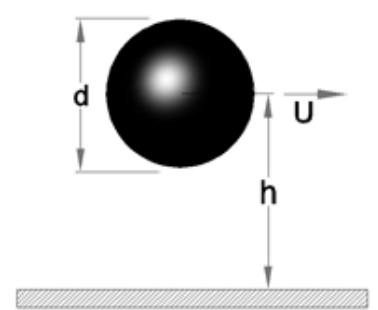

(b) Motion parallel to the wall
Figure 2. Drag acting on a particle moving toward a wall

For very small particles, when the particle size becomes comparable with the gas mean free path, slip occurs and the expression for drag must be modified. Here Cunningham correction factor $\mathrm{C}$ is given by

$$
C_{C}=1+\frac{2 \lambda}{\sigma}\left[1.257+0.4 \exp \left(-1.1 \frac{\sigma}{2 \lambda}\right)\right]
$$

It can be noted that $C_{C} \geq 1$ for all values of $\sigma$ and $\lambda$. [4]

\section{Numerical Model}

Equation 2 can be written by using finite difference explicit form as follows

$$
\frac{N_{i}^{p+1}-N_{i}^{p}}{\Delta t}=\frac{D}{(\Delta y)^{2}}\left(N_{i+1}^{p}-2 N_{i}^{p}+N_{i-1}^{p}\right)
$$

Here $\mathrm{N}$ is the number of molecules and $\mathrm{p}$ is the increment in $\mathrm{y}$ direction and ' $\mathrm{i}$ ' is the increment in $\mathrm{x}$ direction. Now we have to incorporate stability and how it propagates through the system. If the system has less error propagating behaviour from the previous state to the succeeding state then the system is stable. Let us define some variable as follows: $\mathrm{M}=$ Analytical solution of partial differential equation, $\mathrm{D}=$ Exact solution of difference equation, $\mathrm{N}=$ Numerical solution from a real computer with finite accuracy then discretization error $=(M-D)$ and round off error $\varepsilon=$ (N-D). So the equation 13 can be written as follows

$$
\frac{\varepsilon_{i}^{p+1}-\varepsilon_{i}^{p}}{\Delta t}=\frac{D}{(\Delta y)^{2}}\left(\varepsilon_{i+1}^{p}-2 \varepsilon_{i}^{p}+\varepsilon_{i-1}^{p}\right)
$$

Now incorporating von Neumann criterion for studying the linear difference equations stability is as $\frac{\varepsilon_{i}^{p+1}}{\varepsilon_{i}^{p}} \leq 1$ or $\mathrm{Fo}_{m} \leq 0.5$ which is the stability requirement. Here $\mathrm{Fo}_{\mathrm{m}}$ i.e. Fourier mass transfer can be written as $\frac{D \Delta t}{(\Delta y)^{2}}$ [1]. Now for finite volume case equation 2 can be written as for node 1 by considering each node distance as $0.1 \mathrm{~m}$ and the direction is north- south direction where the sheath mass is emanated from north to south direction due to drag force of the particles of system mass.

$$
\frac{\left(n_{p}-n_{p}^{0}\right) \cdot \Delta y}{\Delta t}=\frac{D \times\left(n_{n}^{0}-n_{p}^{0}\right)}{\Delta y}
$$

And similarly for grid 10 the equation 2 can be written as

$$
\frac{\left(n_{p}-n_{p}^{0}\right) \cdot \Delta y}{\Delta t}=\frac{2 D}{\Delta y}\left(n_{B}-n_{p}^{0}\right)-\frac{D}{\Delta y}
$$

Now in standard form the equation of nodes can be written as

$$
a_{p} n_{p}=a_{s} n_{s}^{0}+a_{n} n_{n}^{0}+\left(a_{p}^{0}-\left(a_{n}+a_{s}\right)\right) n_{p}^{0}+s_{u}
$$

Where $a_{p}^{0}=a_{p}=\frac{\Delta y}{\Delta t}$ and the values of other coefficients at various nodes from equation $14 \& 15$ is as follows

Table 1. Value of coefficients at each node

\begin{tabular}{|c|c|c|c|}
\hline Node & $\mathrm{a}_{\mathrm{s}}$ & $\mathrm{a}_{\mathrm{n}}$ & $\mathrm{s}_{\mathrm{u}}$ \\
\hline 1 & 0 & $\frac{D}{\Delta y}$ & 0 \\
\hline $2,3,4,5,6,7,8,9$ & $\frac{D}{\Delta y}$ & $\frac{D}{\Delta y}$ & 0 \\
\hline 10 & $\frac{D}{\Delta y}$ & 0 & $\frac{2 D}{\Delta y}\left(n_{B}-n_{p}^{0}\right)$ \\
\hline
\end{tabular}

The time step for the explicit method can be found from von Neumann criterion. Here $s_{u}$ is the generation term.[14]

\section{Results and Discussions}

For drag force acting on the particle we need to have viscosity, velocity, particle size and Cunningham factor values. From equation (3) and the data's from 'B.1, A.5\&A.19' table [7] we have particle sizes and molecular weight for the five media is as follows

Table 2. Composite media's sizes

\begin{tabular}{|c|c|}
\hline Media & Particle size $(\AA)$ \\
\hline Air-argon & 3.63 \\
\hline Air-He & 3.13 \\
\hline Air-Krypton & 3.7 \\
\hline Air-Neon & 3.3 \\
\hline Air-Xe & 3.9 \\
\hline
\end{tabular}

Table 3. Molecular weight of composite media's

\begin{tabular}{|c|c|}
\hline Media & Molecular weight $(\mathrm{g} / \mathrm{mol})$ \\
\hline Air-Argon & 33.61 \\
\hline Air-He & 7.035 \\
\hline Air-krypton & 43.10 \\
\hline Air-Neon & 23.8 \\
\hline Air-Xe & 47.506 \\
\hline
\end{tabular}




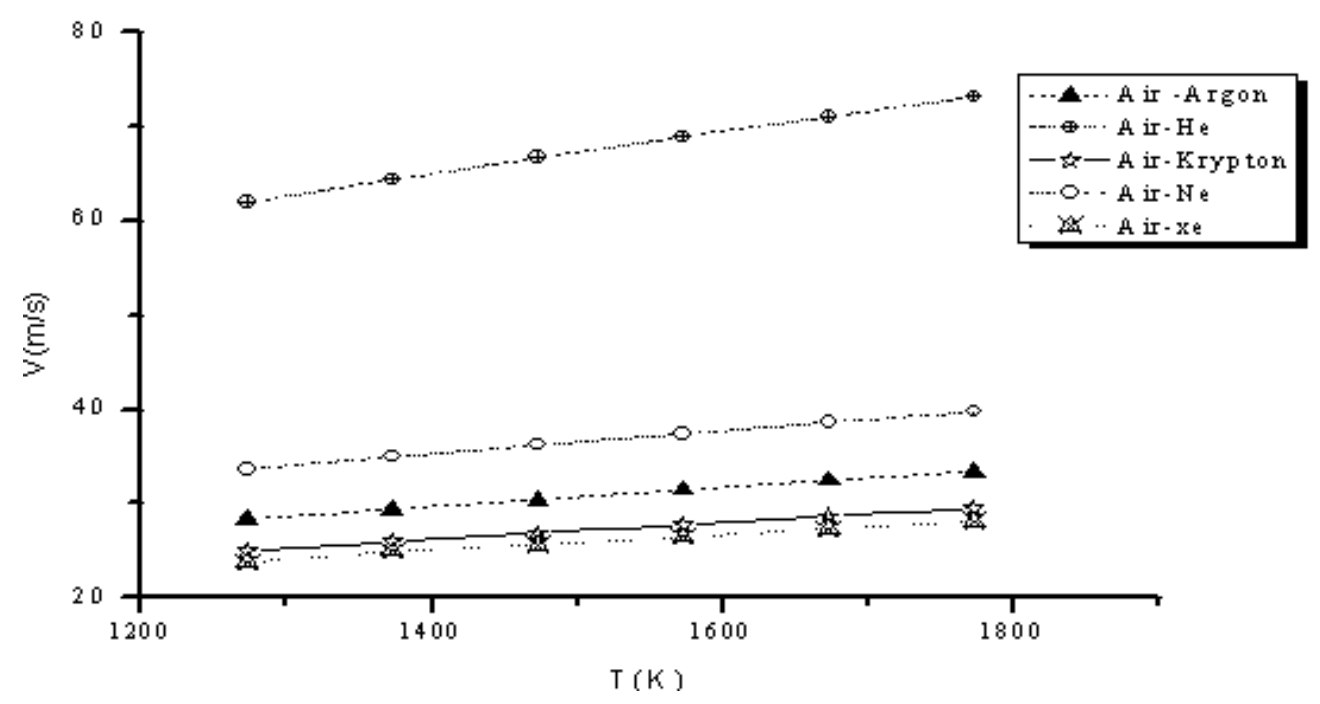

Figure 3. Variation of velocity with temperature

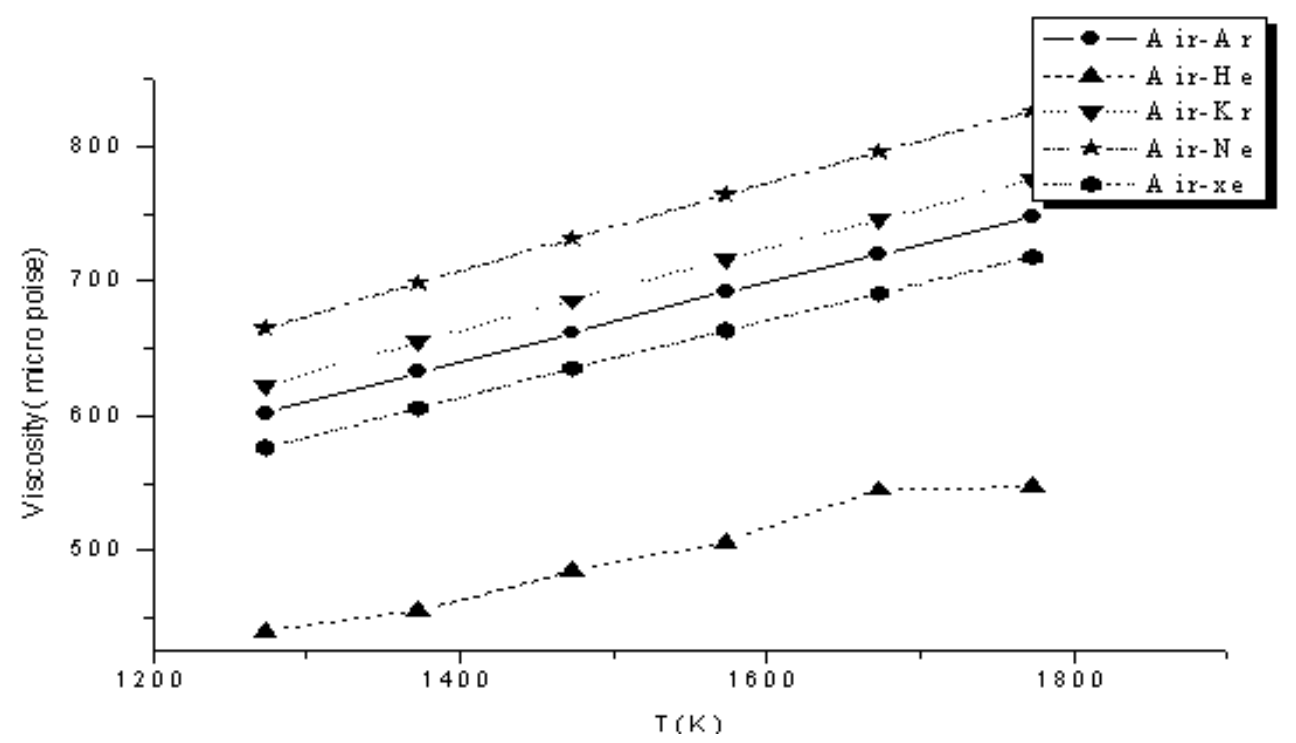

Figure 4. Variation of viscosity with temperature

Now for average molecular speed for the five media at different temperatures from $1000^{\circ} \mathrm{C}$ to $1500^{\circ} \mathrm{C}$ is shown in fig. So velocity for Air-Helium system is more and Air -Xe system is less i.e. we will recommend Air-Xe media for better life of thermocouple sheath. Now for collision integral $\left(\Omega_{\mathrm{D}}\right)$ for finding the viscosity and viscosity variation in different temperatures is as follows

Table 4. Collision integral of composite media's particle

\begin{tabular}{|c|c|c|c|c|c|}
\hline $\mathrm{T}(\mathrm{k})$ & $\Omega_{\text {Air-Ar }}$ & $\Omega_{\text {Air-He }}$ & $\Omega_{\text {Air-Kr }}$ & $\Omega_{\text {Air-Ne }}$ & $\Omega_{\text {Air-Xe }}$ \\
\hline 1273 & 0.696 & 0.5855 & 0.733 & 0.6413 & 0.75 \\
\hline 1373 & 0.688 & 0.588 & 0.724 & 0.634 & 0.74 \\
\hline 1473 & 0.681 & 0.5723 & 0.716 & 0.627 & 0.731 \\
\hline 1573 & 0.673 & 0.566 & 0.708 & 0.6204 & 0.723 \\
\hline 1673 & 0.667 & 0.560 & 0.702 & 0.614 & 0.7163 \\
\hline 1773 & 0.661 & 0.5559 & 0.695 & 0.609 & 0.709 \\
\hline
\end{tabular}


Table 5. Mean free path of the various media's

\begin{tabular}{|c|c|c|c|c|c|}
\hline $\mathrm{T}(\mathrm{k})$ & $\begin{array}{c}\boldsymbol{\lambda}_{\text {Air-Ar }} \\
(\mathrm{nm})\end{array}$ & $\begin{array}{c}\boldsymbol{\lambda}_{\text {Air-He }} \\
(\mathrm{nm})\end{array}$ & $\begin{array}{c}\boldsymbol{\lambda}_{\text {Air-Kr }} \\
(\mathrm{nm})\end{array}$ & $\begin{array}{c}\boldsymbol{\lambda}_{\text {Air-Ne }} \\
(\mathrm{nm})\end{array}$ & $\begin{array}{c}\boldsymbol{\lambda}_{\text {Air-Xe }} \\
(\mathrm{nm})\end{array}$ \\
\hline 1273 & 296.33 & 398.6 & 285.22 & 358.55 & 256.72 \\
\hline 1373 & 319.6 & 419.6 & 307.62 & 386.72 & 276.9 \\
\hline 1473 & 342.9 & 461.17 & 330.025 & 414.9 & 297.045 \\
\hline 1573 & 366.152 & 492.98 & 352.43 & 443.043 & 317.21 \\
\hline 1673 & 389.43 & 523.8 & 374.831 & 471.21 & 337.4 \\
\hline 1773 & 412.7 & 555.1 & 397.234 & 499.4 & 357.54 \\
\hline
\end{tabular}

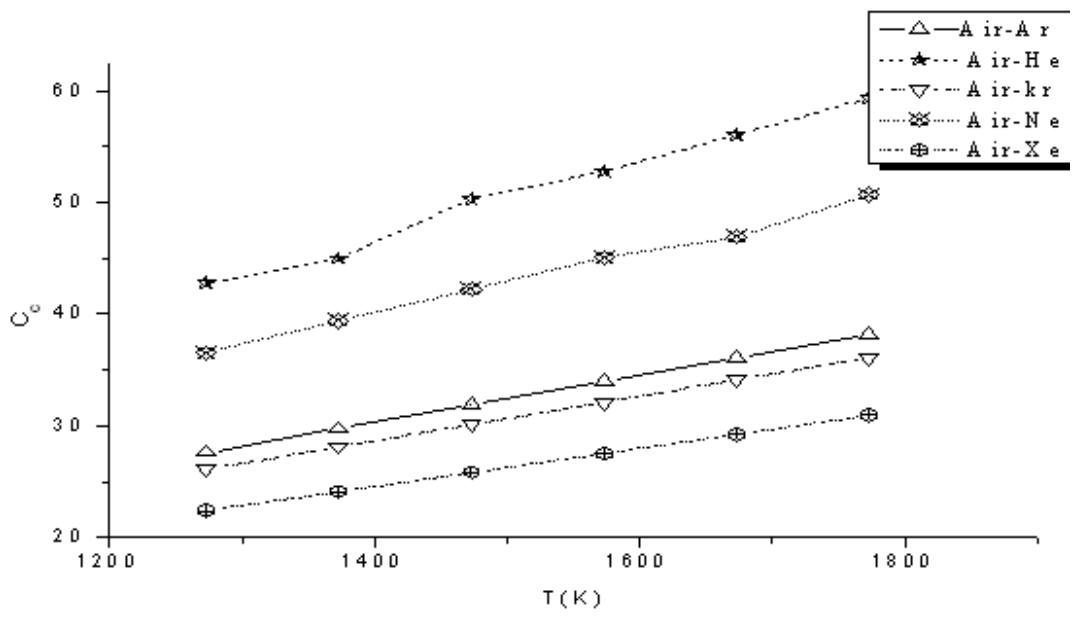

Figure 5. Variation of Cunningham correction factor with temperature

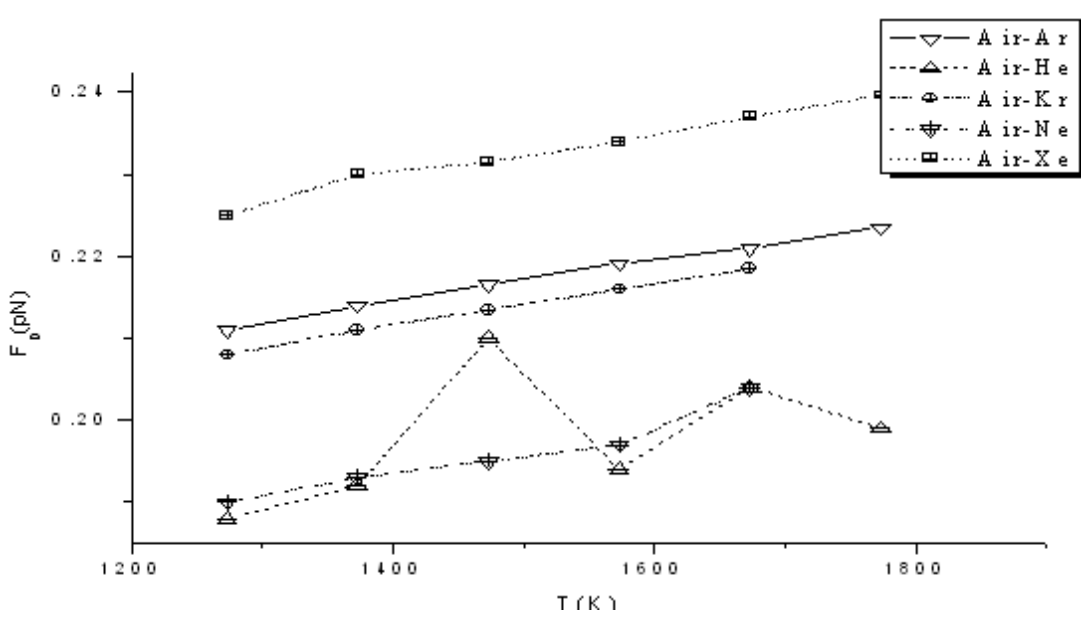

Figure 6. variation of drag force (in Pico Newton) with temperature (in K)

Here Cunningham factor for 5 media at various temperatures by evaluating the mean free path by equation (6) is shown above (fig 5) and the drag force can be calculated from equation (10) and it has been seen from above plot (fig 6) that drag force is maximum for Air-Xe media and minimum for Air-He or Air-Ne. We want to control both velocity and drag force for better life of thermocouple's outer sheath. But Air-He system particle velocity is more than Air-Ne system. So we recommend Air-Ne media for better control and reliability of the thermocouple. Now we using von Neumann stability criterion for calculating time step and at temperature $1273 \mathrm{~K}$ and $1 \mathrm{~atm}$. pressure the diffusivity can be calculated from equation (9) is $3.54 \mathrm{~cm}^{2} / \mathrm{s}$. It can be shown that the particle concentration with space and time first increases then decreases exponentially from contact region of the thermocouple sheath to the atmospheric region with time by taking $1 \mathrm{~m}$ length 2D geometry and incorporating 10 grids and distance between 2 grids is $0.1 \mathrm{~m}$. Concentration at each grid can be finding from the equation (3). So the variation particle concentration with time and space by taking $\mathrm{N}_{0}=1 \mathrm{~mol} / \mathrm{m}^{3}$ is as follows 


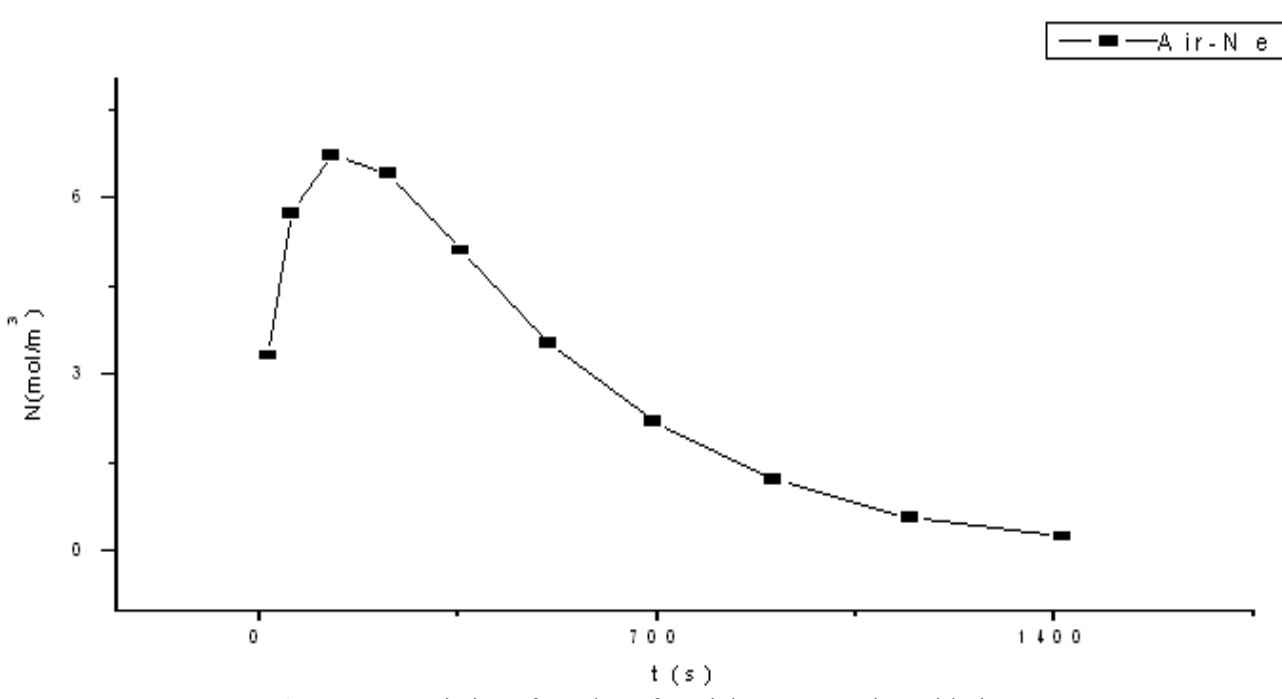

Figure 7. Variation of number of particle concentration with time

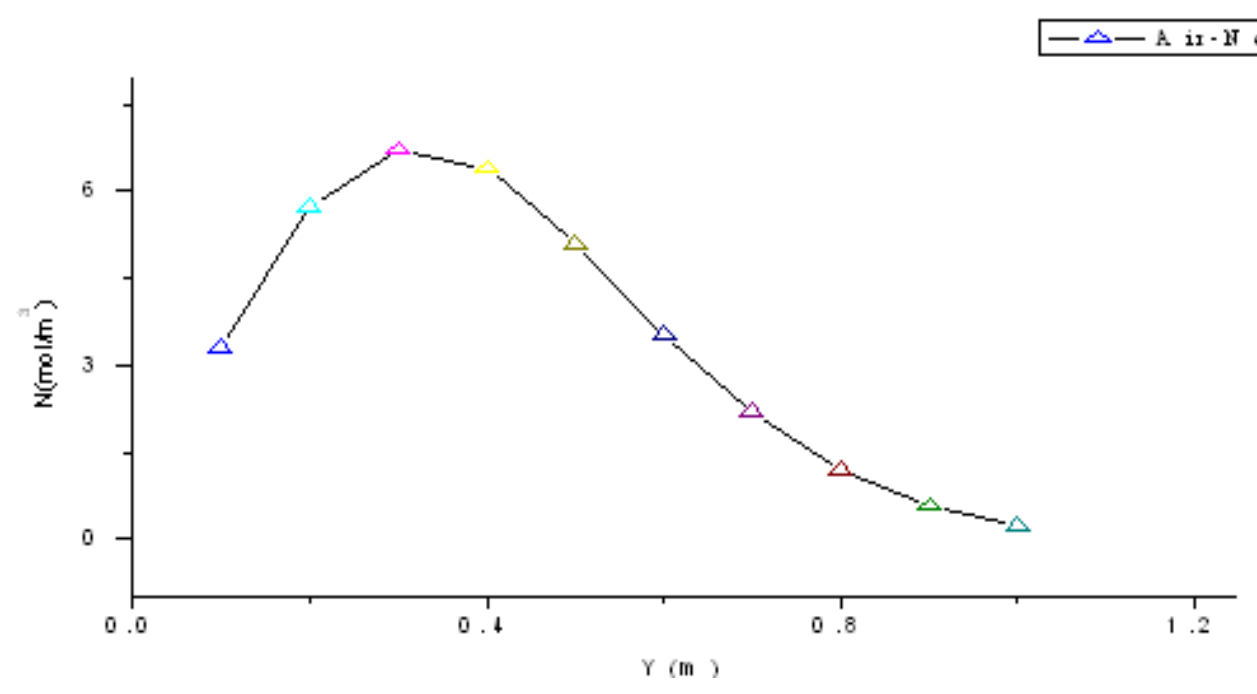

Figure 8. Variation of number of particle concentration with space

Now for finite volume method the values of concentration volume at each grid can be finding by using equation (17) is as follows

$$
\begin{gathered}
0.0071 n_{p}=0.00354 n_{n}^{0}+0.00356 n_{p}^{0} 0.00354 n_{p}=0.00177 n_{s}^{0}+0.00177 n_{n}^{0} \\
0.00236 n_{p}=0.00188 n_{s}^{0}+0.00188 n_{n}^{0} 0.00177 n_{p}=0.000885\left(n_{s}^{0}+n_{n}^{0}\right) \\
0.001416 n_{p}=0.000708\left(n_{s}^{0}+n_{n}^{0}\right) 0.00118 n_{p}=0.00059\left(n_{s}^{0}+n_{n}^{0}\right) \\
0.00101 n_{p}=0.0005057\left(n_{s}^{0}+n_{n}^{0}\right) 0.000885 n_{p}=0.0004425\left(n_{s}^{0}+n_{n}^{0}\right) \\
0.00079 n_{p}=0.000393\left(n_{s}^{0}+n_{n}^{0}\right) 0.00071 n_{p}=0.000354\left(n_{s}^{0}-n_{p}^{0}\right)
\end{gathered}
$$

By solving this equation we get succeeding nodes value is almost same $0.02 \mathrm{~mol} / \mathrm{m}^{3}$.not much variation is there.

\section{Conclusions}

We have seen from the plot 3 and 6 is that drag force is maximum for Air-Xe media but minimum for Air-He or Air-Ne. Also we observed that particle velocity of Air-He media is more than Air-Ne. For better control of the system parameters and for the system reliability we want to control both velocity and drag force. In numerical work Air-Ne media does not shown too much variation in concentration and its concentration decreases from the top of the sheath contact with time. So we recommend Air-Ne media for better life of thermocouple outer sheath. 


\section{Scope of Future Work}

Many more variations can be shown by taking this type of inert media's. By incorporating deeper concept like particle physics we can describe this kind of work more deeply and for preparing the improvement of the system we can use fuzzy logic and neural network for better control and good system performance. Aerodynamic motion of the particles can be studied while collide with sheath particle mass.

\section{REFERENCES}

[1] Anderson D John "Computational fluid dynamics-the basics with application" McGraw-Hill international, 1995,pp-171-187

[2] Bergman L. Theodore, Lavine S. Adrienne, Incropera P. Frank, Dewitt P. David "Fundamentals of Heat and Mass Transfer-seventh edition”, John Wiley and sons , pp 965-967

[3] Castro Pedro "Thermocouple Sensors "Presentation ,pp-5

[4] Clarkson University online page " Fluid mechanics of Aerosols", National Science Foundation
[5] Platinum Metals Review ,1969 , 13(3), pp-93-94

[6] Platinum Metals Review,1971,15,(3),pp: 82-89

[7] Poling B.E., Prausnitz J.M., O’Connell J.P. "The properties of gases and Liquids" McGraw-Hill, 5th ed., 2000.,pp-9.3,9.5,9.9,B.1,11.5,A.5,A.19

[8] Scervini Michele, Rae Catherine " An improved Nickel based MIMS thermocouple for high temperature Gas turbine applications" ASME vol.135,September 2013,pp-91601-1-3

[9] Department of Material Science and Metallurgy, University of Cambridge "Thermoelectric Materials for Thermocouples.

[10] "Thermocouple-type temperature-detecting device",2003, US patent application,US6632018B2,pp-2

[11] Wergner K. “Estimation of diffusivities" presentation Swiss federal institute of Technology Zurich,2012 pp-5-7

[12] Wikipedia of thermocouple.

[13] "Standard Specification for Type $\mathrm{K}$ and Type $\mathrm{N}$ Mineral-Insulated, Metal-Sheathed Thermocouples for Nuclear or for Other High-Reliability Applications" ASTM E235/E235M - 12

[14] Versteeg HK, Malalasekera W “ An introduction to computational fluid dynamics-The finite volume method" Longman Scientific \& Technical, 1995, pp 86-91. 